\title{
The Needs Analysis Procedures and Tools Design of Non- English- Background Job Seekers with a Critical Evaluation of Different Approaches to Language Curriculum Development
}

\author{
Jianna Qiu ${ }^{1, a}$ \\ ${ }^{1}$ School of Foreign Languages, Quanzhou Normal University, Quanzhou, Fujian, China \\ aqujianna@163.com
}

\begin{abstract}
Keywords:Needs analysis, Non-English-background, Job seekers, Language curriculum development.
\end{abstract}

Abstract. This paper makes a research on the needs analysis procedures and tools of a group of learners who would need English for a specific purpose (ESP), non-English- background job seekers specifically, with a critical evaluation of different approaches in order to lay a solid foundation for language curriculum development.

\section{Introduction}

In the context of TESOL (Teaching English to Speakers of Other Languages), curriculum development includes the processes that are used to determine the needs of a group of learners, to develop aims or objectives for a program to address those needs, to determine an appropriate syllabus, course structure, teaching methods, and materials, and to carry out an evaluation of the language program that results from these processes (Richards, 2001, p. 2) ${ }^{[1]}$. As learning is basically an interaction between teachers and students, teaching methods and approaches used will simultaneously have a great effect on curriculum development, which will be briefly and critically demonstrated on the one hand, while on the other hand the needs analysis procedure and tools of a group of learners who would need English for a specific purpose (ESP), non-English- background job seekers specifically in this paper, will be designed and analysed in order to lay a solid foundation for the curriculum development in the foreseeable future.

\section{A Critical Evaluation of Different Approaches to Language Curriculum Development}

Language curriculum development makes its evolution with the increase of knowledge about language and language learning, of which the most representative and practical factor is language teaching approaches, because teachers' task is to make the teaching more appropriate and efficient through integrating and improving a variety of teaching approaches.

In the early periods, teaching approaches such as Grammar-translation with the emphasis on written language, accurate translation and the use of text book based on the categories of traditional Latin-based grammar are far from being practical, although the accurate grammar is achieved. Later on, the Situational and Audio-lingual approaches make some improvements on the usage of specific settings such as dialogues through repetition and habit formation. With the rapid development of language learning and teaching, more and more language teaching approaches make their progress such as Communicative Language Teaching (CLT).

Communicative Language Teaching (CLT) focuses on communication as the organising principle. Littlewood in 1981 said that "one of the most characteristic features of Communicative Language Teaching is that it pays systematic attention to functional as well as structural aspects of language" [2], which means that besides language itself on the aspects of structures lexically and grammatically, the social functions of language under different contexts are explored and used during the process of Communicative Language Teaching (CLT). According to Richards (n.d.) in Communicative Language Teaching Today, there are two directions in current methodology. One is Process-based approaches 
including Content-based Instruction and Task-based Instruction, while the other one is Product-based approaches including Text-based Instruction and Competency-based Instruction ${ }^{[3]}$.

Content-based Instruction. It is teaching language around a theme or topic and not around a specific language skill or grammar point (Plourde \& Silina, n.d.) ${ }^{[4]}$. In other words, English language here is used as a means of acquiring information, not an end in itself, which is the most essential and practical factor of Content-based Instruction compared with other instructions. In this way, learners' needs are reflected and satisfied accordingly in a coherent framework to link and develop language skills. However, these mutual benefits of knowledge and language acquisition will consequently lead to be less competent in the appropriateness and precision in English language.

Task-based Instruction. According to its principles, active learning learners learn best by actively using the language they are learning, and learners should be taught in ways that make clear the relationships between grammatical form, communicative function, and semantic meaning (Nunan, 2002) ${ }^{[5]}$. In this sense, Task-based Instruction is comprehensive and lays a solid foundation for English language learners. However, the process of doing tasks is abstract to some extent and not preferred by learners with a desire to find activity or diversion.

Text-based Instruction. Text-based Instruction is based on an approach to teach language that involves teaching the structures and grammatical features of spoken and written texts (Richards, n.d.)

${ }^{[6]}$. On the other hand, the analysis of texts is linked to a certain cultural context to make learners be correct and appropriate in expression and communication. The language and cultural points are covered and delivered during the process of Text-based Instruction, but the choice of texts is the vital factor, because the most effective teaching is built on appropriate teaching materials.

Competency-based Instruction. The characteristic of Competency-based Instruction is its focus on social functions and life skills of English language (Richards, n.d.) ${ }^{[7]}$. Due to its modularized instruction, explicit outcomes and continuous assessment, it is one of the most practical methods in English language teaching, especially for learners of advanced level. Nevertheless, any instruction should be linked with the society in order to make changes and improvements such as the modules and the assessment system.

\section{The Needs Analysis Procedures and Tools Design of Non- English- Background Job Seekers}

A variety of issues are to be considered in designing a language curriculum. First of all, the general and particular role of learning English ought to be clear. Moreover, the nature of English language should be made known. Finally, different groups of learners are to be identified. During the process of TESOL curriculum development, there are ten steps:

1 Developing policy.

2 Analysing needs.

3 Determining aims and objectives.

4 Selecting methodologies and methods.

5 Selecting resources and materials.

6 Training teachers.

7 Implementing the curriculum in the classroom.

8 Responding to the curriculum in the classroom.

9 Assessing learner progress and achievement.

10 Evaluating the curriculum.

This part will focus on the design of a needs analysis procedure and tools in order to identify the factors determining the nature of the curriculum to be developed and decide on the information related to the curriculum development. In this paper, the imaginary clients are a group of non-English-background learners who would need English for a specific purpose (ESP), which is seeking jobs. In other words, they are job seekers with English as their second or foreign language from a variety of cultural backgrounds and English levels. In investigating the needs of these non-Englishbackground job seekers, the following procedure will be conducted according to the division of 
non-language learning needs, language learning needs, personal needs and specific purpose needs respectively.

Non-language Learning Needs. First of all, the background profiles of the job seekers are required so as to have a general understanding about the learners. It could be undertaken in the form of a brief questionnaire including questions such as gender, age, nationality, vocation, first language, second language, years of learning English and educational experiences.

Language Learning Needs. As far as English language learning is concerned, there are basically four skills, which are listening, speaking, reading and writing. In order to have a command of the English level of learners, tools such as self-ratings with checklists, interviews, task analysis and collecting learner language samples are used to collect information.

In terms of self-ratings, learners are expected to complete a questionnaire with questions concerned with their comprehensive English level from their own perspectives and experiences.

During the process of interviews, learners are expected to have a communication and interaction with the interviewers. Based on this, the listening and speaking level of learners could be demonstrated. In the meantime, by the consent of learners, the process of the interview is suggested to be recorded as the data for future analysis such as pronunciation.

In detail, on the part of reading, learners are required to read a job advertisement in the newspaper and make a call to inquire about and apply for the job, which could meanwhile work as an example of task analysis. In respect of writing, learners are expected to write a job application letter to demonstrate their performance in writing skills so that the learner language samples are collected in this way.

Personal Needs. With reference to the personal needs of learners, tools such as questionnaire, discussion, meeting and observation are used to obtain their interest and barriers to learning.

In the questionnaire, questions referring to the interest and barriers to learning will be mentioned in the form of being open and close, which provides more freedom for learners to make an expression. Other than that, the discussion and meeting will be organized in order to provide an open and free atmosphere for learners to make a communication with teachers and colleagues, hence a direct feedback through the observation of learners' behavior in a target situation will be acquired in a factual and effective way. Furthermore, it should be pointed out that the understanding of learning barriers like being practical, personal, family-related, social or economic is the direct step in preparing for meeting the needs of learners.

Specific Purpose Needs. In view of the specific purpose of the non-English-background job seekers, their vocational goals are expected to be made known through questionnaires and interviews, which is the key factor in designing the procedure of needs analysis.

From the perspective of the whole society, a survey needs conducting in order to make it clear that what the popular and competitive jobs are at present and what are the most important skills in seeking a job. This survey will be undertaken randomly among friends or strangers from different cultural backgrounds and different fields so as to have a comprehensive understanding about job seeking.

In addition, in order to meet the specific purpose needs of job seeking, a certain target population will be involved ranging from teachers, employers, vocational training specialists to employment agencies.

First of all, teachers are expected to take part in the interview in the real environment to get the real feeling and experiences of job seekers. It means that they could act as an applicant to apply for a job through calls or in person, or alternatively opportunities might be provided for them to witness and record the procedure of various job interviews, according to which the first handed teaching materials and data would be gathered and analyzed.

As the counterpart of job seekers, employers play a vital role in the job interview. In this sense, the criteria and requirements of employers are essential for job seekers. As a result of this, a random survey could be carried out among employers with the purpose of obtaining their needs and practical skills of job seeking. 
On the other hand, vocational training specialists and employment agencies could offer appropriate and timely aid. As specialists in vocational training, they are good at teaching job seekers how to cope with the situation appropriately during the process of job seeking including speech, dress and behavior, while with the help of employment agencies, the timely information about the jobs and the market will increase the possibility of acquiring the job successfully. In consequence, the frequent contact and consultation with vocational training specialists and employment agencies is another worthwhile resource to help the needs analysis of non-English-background job seekers from an objective perspective in the context of the whole society.

\section{Conclusions}

In conclusion, the procedures and tools involved in the process of designing the needs analysis of a group of non-English-background job seekers will be briefly listed in the following. Due to the subjective and objective limitations, there are obvious disadvantages, but it is still expected that they will make a preparation for the curriculum development in the foreseeable future.

1 Design, analyze and review a questionnaire according to the four needs types.

2 Undertake a survey by means of the designed questionnaire.

3 Organize a discussion and meeting among learners and teachers and conduct the classroom observations.

4 Interview volunteer participants, because the individual interviews are not compulsory.

5 Conduct the social survey to have a general understanding about job seeking, involve teachers in job-seeking practice and consult employers, vocational training specialists and employment agencies constantly.

6 Develop a schedule for collecting data.

7 Analyze responses.

8 Write up report and recommendations.

\section{References}

[1] Richards, J. C. (2001). Curriculum development in language teaching. Cambridge: Cambridge University Press.

[2] Littlewood, W. (1981). Communicative language teaching: An introduction. Cambridge: Cambridge University Press.

[3,6,7] Richards, J. Communicative language teaching today. (n.d.). English Language Teaching. Retrieved September 16, 2015, from http://www.professorjackrichards.com

[4] Plourde, P., \& Silina, O. Strategies in teaching content-based courses to English language learners. (n.d.). MIDTESOL. Retrieved September 26, 2015, from http://www.midtesol.org/Newsletter/2001winter-SilinaArticle.htm

[5] Nunan, D. (2002). Second language teaching and learning. Peking: Foreign Language Teaching and Research Press. 